\title{
GENERATING A GENDER BALANCE: MAKING INTRODUCTORY INFORMATION SYSTEMS COURSES A POSITIVE EXPERIENCE
}

\author{
Rosemary Stockdale \\ Institute of Information and Mathematical Sciences \\ Massey University, Auckland, NZ \\ Email: r.j.stockdale@massey.ac.nz \\ Susan Stoney \\ School of Management \\ Edith Cowan University, Perth, Australia \\ Email: s.stoney@ecu.edu.au
}

\begin{abstract}
There is a growing shortfall of graduates entering the IT profession. The situation is exacerbated by the continuing decline in the number of women undertaking IT related degrees. However, there are an increasing number of students taking business degrees that have a small information systems component, although few students choose to major in IS. Using a qualitative reflective approach we identify the perceptions and experiences of female undergraduates taking introductory IS courses in two universities, one in Australia and one in New Zealand. We discuss ways of improving the delivery of introductory IS courses in order to make information systems more interesting to women undergraduates, thus enhancing their learning experiences and encouraging further uptake of IS majors. The paper concludes with some reflections on other influences that impact on the ability of IS departments to deliver appropriate introductory courses.
\end{abstract}

\section{INTRODUCTION}

There is a real and growing shortage of information technology (IT) professionals in the workplace (Department of Labour, 2005), in both traditional and non-traditional areas such as supply chain management and education (Sujdak, 2002). Whilst there are over 45000 hits on Google Scholar regarding the shortage of IT professionals generally, there are over 63,000 that specifically address the shortage of women. 
The declining number of women in IT is well-documented in both the business press and in academic research. The reasons given for the decline are many and varied. Armstrong, Riemenschneider, Ried \& Allen's (2004) study discusses women who have followed an IT career path but then leave the profession. The authors conclude that the reasons are contained within three loops; managing family, need for flexibility of work schedule and stress. This is borne out by an Department of Women (Australian) report (2002), which found that women who work in the IT industry rate it highly for flexibility and career support, but very low when it came to a family friendly workplace. These findings are reflected across all industry sectors where there are a steady stream of women in all professions who opt out of the workplace after five to ten years. Work-life balance and difficult workplace environments are major factors in this drain of experienced, professional women leaving their careers (Stone, 2007). However, this does not explain why women are not entering the IT professions in the first place. Fewer women are studying IT related courses with a consequent impact on their future careers

Whilst the work-life balance is an established reason for women leaving the IT profession, it does not explain why women are not entering the profession. The lack of interest in IT is already evident in university enrolments where the number of women studying IT-related courses continues to decrease, with a consequent impact on their future careers.

High enrolment levels in business degrees mean that many women are exposed to information systems (IS) courses as first year undergraduates. These courses are often compulsory for business students and can be seen as an opportunity to recruit more students to IS majors via a business pathway. Our research suggests that such courses are unpopular with female undergraduates and do not attract them to consider changing from business studies to IT related majors.

The contribution of this paper is to determine ways to develop more positive experiences of studying for an IT related degree. We concentrate specifically on introductory IS courses and determine what steps we, as academics responsible for teaching these courses, need to take to encourage greater uptake of IS majors by women. This paper addresses the first steps taken towards a proactive process of change to achieve a greater gender balance in IS courses at our two universities, one in New Zealand and one in Australia. We have taken a qualitative approach to analysing the current situation regarding the delivery and marketing of information systems courses. Using our own experiences as course co-ordinators for Introductory Information Systems, we use focus groups and interviews to identify student perceptions of the courses. Subsequent analysis of the data, underpinned by existing literature, has enabled us to identify where improvements can be made to encourage a more balanced gender distribution in IS degrees.

Although this paper specifically addresses IS courses, the literature encompasses the broader spectrum of IT as the issues relating to the IT sector include those of IS and the latter is rarely addressed separately. The term IT is therefore used in its widest sense, although we have avoided literature that specifically addresses computer science and software engineering.

\section{THE GENDER GAP IN INFORMATION TECHNOLOGY}

"As an industry some of our role models aren't necessarily the coolest people out there. I'm not sure that Bill Gates, for example, is the natural turn-on for a 12 year old girl"

(Katrina Troughton, IBM NZ Managing Director)

Technology is stereotypically seen as a male domain in a popular culture that continues to associate occupations with either a male or a female bias (Lee, 2005). Despite arguments that gender is no 
longer an issue in a dynamic labour market where there is a high demand for IS professionals (Sumner \& Niederman, 2004) women account for less than $20 \%$ of the IT workforce (Goodwin, 2006).

This has become a political issue as the lack of women in IT amounts to a classic example of horizontal occupational segregation (Griffiths, Keogh, Moore, Tattersall, \& Richardson, 2006). Griffiths et al., explain that horizontal occupational segregation shows how different groups of people, often defined by gender, tend to work in separate occupations. Women are often clustered in traditional careers; teaching, nursing, and domestic service work (Anker, 1998 cited in Griffiths, et al., 2006). Furthermore, within particular industries, women tend to be under-represented at the higher managerial levels (such as Chief Information Officers in IS), and are more strongly represented in lower level occupations. This is a identified as vertical gender segregation.

Much of the research on women in IS and IT related managerial positions focuses on the workgender imbalance (Griffiths et al., 2006; Griffiths \& Moore, 2006; Moore, Griffiths, \& Richardson, 2005), citing the unsuitability of the IT workplace, the deeply ingrained masculine culture of IT, the long hours, "presenteeism”, and difficulties with obtaining part-time employment.

The reasons attributed to the gender imbalance also focus on the different attitudes to computer technology where women are seen as computer-phobic or computer reticent (Turkle in Christensen, Knezek, \& Overall, 2005). IT has an image problem where boys who excel at computing are seen as 'nerds', 'geeks' or 'trainspotter types' with a lack of social skills (Lee, 2005) while girls are perceived to be more social and find IT subjects in school 'boring'. Research suggests that lack of role models and the occupational culture of IT project a negative image to women (Sumner \& Niederman, 2004). Lack of career information for a technology orientated career is another cited problem (Morris, 2002) and research has found that women lack confidence in their own abilities and assess their skills at a lower level than their male peers (Hargittai \& Shafer, 2006). These issues are less prevalent for females with a family member or friend in the IT industry as this contributes to a more accurate picture of such careers than those who relied on second hand knowledge (Lee, 2005).

Pinkard adds unequal access and an adverse climate in higher education as barriers to encouraging women into IT (2005). She argues that a key cause of the different attitudes towards computer use is the perception of software as male orientated with stereotypical characteristics that did not target or attract women. This identification of software as dominantly male resonates through the literature (Baroudi \& Igbaria, 1995; Morris, 2002; Trauth, 2002). Lee (2005) states that not only software but technology "is gendered from the outside by those appropriating it rather than necessarily on the inside or at the point of design” (p123). This argument supports research into the consideration of two viewpoints into perceptions of IT and gender: essentialist theory versus social construction theory (Trauth, 2002).

Essentialist theory is based on the assertion of inherent differences between the nature of men and women. This argues that biological determinants dictate reaction to IT and we must therefore concede that women will require different methods of training than men to enter the IT workforce (Trauth, 2002). The implications for bridging the gender divide at school and university levels are significant.

The identification of 'gendering from the outside' (Lee, 2005) adheres to the theory of social construction. If IT is seen as male dominated because of societal perceptions then females are less attracted to the technical workplace and this reinforces the identification of computing as 'men's work' (Trauth, 2002). Agreeing with this theory and addressing the problems it raises are two very different things. 
One significant initiative that addresses the male stereotyping of IT is the ITBeat project in the UK (Lee, 2005). The project aims to make ICT glamorous and appealing to girls by introducing appropriate role models, associating fun with computers and using images that relate to girls' perceptions of themselves. In making computing more of a 'female domain' (Webster in Lee, 2005) the project encourages positive images amongst those girls involved and supports their development of technical knowledge. However, Lee highlights the problem of applying feminine stereotyping and developing gender specific affinities rather than unifying social constructs in a genderless context.

\section{IT/IS EDUCATION AND GENDER}

"The school curriculum doesn't have a lot of credibility.....IT is not regarded as a prestigious subject. It's the sort of thing they quarantine the hopeless into, really"

(T Clear, AUT in Hendery, 2006)

There is widespread concern at the low level of enrolments in IT degrees in many countries (Denning \& McGettrick, 2005). In a recent study across Australia and NZ a recruitment firm found that tertiary IT qualifications were considered of major importance to $77 \%$ of employers surveyed (Rossi, 2006). In NZ universities the total number of students enrolling for IT related degrees has fallen for each of the past four years This was attributed by academics at a recent government conference to the 'geeky image' and lack of broad appeal (Hendery, 2006). Another factor was considered to be the lack of credibility in the school curriculum and the failure of the tertiary sector to adapt to 'what the kids can do with ICT'(Hendery, 2006).

The drop in student numbers is particularly prevalent amongst women; for example in Australia women account for less than one fifth of IT graduates (von Hellens \& Nielsen, 2005). There are several factors that are held to influence the low take-up of IT degrees by women including social and cultural issues (von Hellens \& Nielsen, 2005), lack of role models (Trauth, 2002) and an overwhelmingly male environment (Baroudi \& Igbaria, 1995).

Research into school age children has found that the girls' technical abilities are as good, if not better, than boys at primary age (Christensen et al., 2005). Differences begin to appear after Grade 6 and as children reach high school the enjoyment that girls find in using computers falls. More importantly, there is evidence that their self-assessment of skills declines and they are less confident of their technical abilities (Hargittai \& Shafer, 2006; Jewell \& Maltby, 2002; von Hellens \& Nielsen, 2005). Nevertheless, girls' use of email and their level of web skills remain high and appear to be influenced by the social enjoyment aspects gained from online use (Christensen et al., 2005). In high school, a distinct difference becomes visible in gender attitudes towards computing and IT and the 'geek' image gains more credence, with girls finding the studying of IT to be boring and difficult (Lee, 2005). There is a perception amongst girls of this age that careers in IT lead to a solitary work environment with little contact with people and an emphasis on mathematical abilities (von Hellens \& Nielsen, 2005). They appear to believe that a special aptitude for computing is necessary, while males see computing as a technical challenge that can be mastered (Jewell \& Maltby, 2002). However, it appears from Jewell \& Maltby's study that girls are not deterred by the level of difficulty but rather by the perceived lack of social involvement arising from an IT career.

Girls' aversion to IT related courses may also be affected by the lack of women role models in the teaching profession (von Hellens \& Nielsen, 2005). This point is echoed in Trauth's (2002) call for more women professors of IT and Sumner and Niederman's (2004) observation that less than 7\% of faculty IT positions are held by women. Some support for the role model argument lies with the 
observation that single sex schools have more success in promoting IT as a career (Trauth, 2002) although it is not clear what percentage of IT teaching staff in such schools are women.

Lang (2003) opens up the role model argument to suggest that the inequality in numbers is also evident in other disciplines such as law and medicine, but that these faculties have few difficulties in attracting female students. Therefore image may have a bigger influence than lack of role models on the low numbers of women in the IT discipline. These low numbers, of either gender, have serious consequences for the IT sector and the broader economy. In 2003, the NZ government concluded that the shortage of appropriately educated graduates was a major constraint on the growth of the country’s ICT sector (Department of Labour, 2005); a situation that has not changed.

Lang (2003) also argues that intervention programmes rarely sustain improvement. The concerns of IT education must therefore be addressed at several levels and academics responsible for introductory university IT related courses must play a role in making courses more accessible and relevant to students.

\section{RESEARCH DESIGN}

This paper is based on the experiences of two academics, from New Zealand and Australia, who teach Introduction to Information Systems courses. The Australian case is from a School of Management Information Systems within a Business Faculty while the New Zealand study is drawn from an Information Systems Discipline Group within a College of Sciences.

The studies were originally undertaken independently, with the two researchers beginning collaboration after data collection had commenced. In both cases data were gathered towards the end of semester one, before exam results were known. Two different approaches were taken to the collection of data and while the preliminary content analysis was conducted separately similar guiding themes were used. Collaboration led to a further refinement of data analysis themes as summarised in Figure 1 and the subsequent joint discussion of the results was used to compare and contrast our experiences, again using the themes in Figure 1. A reflective interpretive approach was taken to meet the needs of our research that derive from our efforts to further develop our first year IS courses to make them more applicable, accessible and even enjoyable for female students.

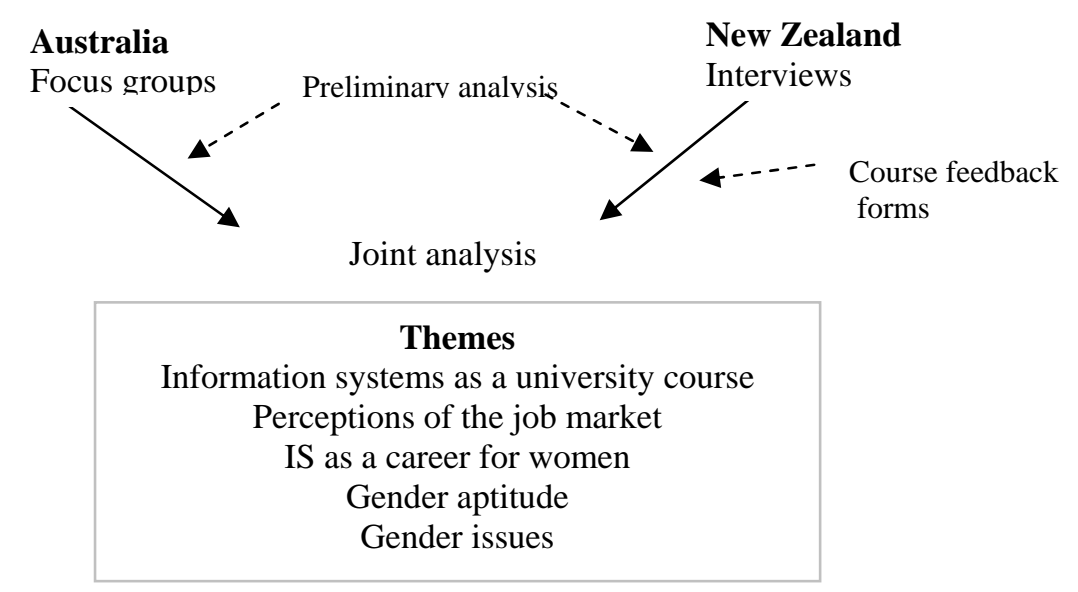

Figure 1: Approach to data collection and analysis 


\section{The Australian experience}

Approximately half of all students studying first year Information Systems are women, and yet less than $10 \%$ of women graduate in an IS discipline. A series of focus groups was used to explore the issues; namely, why women rarely choose an Information Systems major. There were six focus groups in all with six students who had recently passed the course in each group. Three groups consisted of only women, and three consisted of an equal mix of men and women. Groups were drawn from the course cohort and were representative of school leavers and mature age students, and local and international students were equally represented. The focus group sessions lasted for an average of one hour each and extensive notes were taken during the discussions.

\section{The New Zealand Experience}

Introductory Information Systems is a compulsory course for all business and communications students in the NZ university. Therefore slightly more than half of the course are women. Informal, semi-structured interviews were conducted with 14 students (11 female and 3 male students) at the end of semester to explore their perceptions and experiences in taking the course. Interviews lasted an average of 40 minutes and notes were taken and cross checked with the students for confirmation of their accuracy. Additionally, secondary data was extracted from 211 course feedback forms. The forms were not directly related to this research but are commonly used to collect data for course development. The forms are completed anonymously and for the purposes of this research the general comments section was used to identify any comments directly related to gender issues. Such comments were coded and analysed to gain further insights in support of the interview data. Cultural factors were not specifically addressed although we recognise that there are different perceptions between cultures on the issues in technology (von Hellens \& Nielsen, 2005).

\section{STUDENT PERCEPTIONS OF IS COURSES}

The findings from the analysis are discussed in relation to the literature in order to examine the issues that affect female students in regard to IS within the university environment. This supports identification of where changes can be made to improve the learning experience of female students and encourage their greater uptake of IS studies.

\section{Studying Information Systems}

A common facet of teaching IS in the tertiary sector is the lack of understanding of what the term information systems means. First year students rarely show an understanding of what the course might comprise and cannot differentiate IS from other technology courses. Study participants admitted that they were confused as to what constituted IS, with few students able to differentiate between IS and other IT disciplines before the course. Even by the end of semester the majority saw IS as a subset of IT and felt that IS would not give the students as many skills as other IT related majors. This view is exemplified by the following comments:

"yeah, everyone knows what IT is, but who's ever heard of IS?" and “...my friends always ask me to explain what I'm studying, and can't understand what it is perhaps because my own thoughts about it are a bit vague”.

Many of the women involved in the focus groups were headed for the "soft" majors of marketing and management, and felt that IS would not help them in their careers. 
"I look at the jobs that appeal to me and they have titles like 'marketing manager', HR professional - I don't see anything with the words Information Systems."

Even the girls choosing Accounting and/or Finance, felt that IS was “someone else's problem”. These views were articulated repeatedly in the focus groups with comments like:

"everyone understands what an accountant does, but what does an IS professional do? We learn a lot about where it fits into organisations, and how it can lead to a job like a CIO, but I don't know any CIOs, I know accountants and financiers."

"My Dad works for [medium sized company, name withheld], and he reckons that the IS people are there to mop up problems - they only see the problems, don't have a lot of status”.

From a NZ perspective, the understanding of information systems as distinct from IT was addressed early in the course, when it became clear that few students could discern the difference. Responses to 'why IS?' were closely aligned to those of the Australian students with most of the women taking business majors in Management and Finance. Interestingly, it was the men who saw it as necessary to understand the role of IS in business,

"so you can tell your workers what to do and understand what they are capable of".

Excel and Access are taught and tested in practical lab sessions in the NZ case by request of the Business Faculty. Labs are optional and the higher percentage of women attending bears out the argument that women have a less confident view of their own skills (Hargittai \& Shafer, 2006).

"I found the labs really difficult. I had a problem learning Excel although Access was easier. I think it will be useful but I didn't enjoy the labs."

The difference in ability was not reflected in the lab outcomes where test results were even across the genders. Both the interviews and the feedback forms showed that women were more positive about the use of these software applications, and the male students thought that learning them was a 'waste of time'.

\section{IS as a job and IS as a career}

Despite discussion of the roles of chief information officers within lectures, almost all the students saw a career in IS as sitting in front of a computer all day, either programming or manipulating software. Only two Australian students (both men) understood that IS is a 'people' profession, involving talking to people, understanding job requirements, making decisions and managing effectively based on the information provided by the system. All the women felt that a job in IS would be "boring" or "uninspiring", with constant effort required to keep up to date, reflecting the argument that IT disciplines have an image problem (von Hellens \& Nielsen, 2005). The women also saw IS as a "nerdy" profession, and cited the stereotype of the "geek" living in a solitary, antisocial world (Lee, 2005).

"I want to work in a social environment. Computers and things don't give you that I think you just sit there all day facing a screen.”

Not one of them saw the area as dynamic or exciting. Many of the women felt that if they were to major in IS they would be relegated to jobs in web design or simply users of a system. They had no concept that they could have input into the design of the system itself, or that they could influence the ways in which technology was used in an organization.

In NZ, a positive experience was found in the use of guest lecturers who were able to relate IS to the lives of the students. This was particularly true in health informatics, mobile business and security where feedback from students was overwhelmingly positive. These were topics that bore direct relevance to student lives and could be seen as support for the argument of role models in that 
feedback forms had comments such as "I could see myself doing that" "using IS in health care really contributes to society" (Sumner \& Niederman, 2004) and

"the guest lecturers were really interesting. I could relate to what they said because

it was real. The security stuff was great."

From a career perspective, the reflections on the perceived employment tasks were mirrored in a lack of enthusiasm for pursuing a career in IS, with virtually no students planning a career in this sector.

“...look I've done the first IS unit and I can't see IS as being something that would get me promoted at work. I know it's useful as a tool, but I can't imagine doing it for a living."

In the Australian university two of the women and five of the men agreed that IS could be a worthwhile career for women, but when asked why, they struggled to articulate any reasons. This reflected the case in NZ where only one of the women interviewed had any intention of working in an IS career. This student is a Pacific Islander and wished to contribute to her country's urgent need for more trained IT people; an ambition more in line with the traditional career choice of contributing to society that underpins the dominance of women in the so-called caring professions (Griffiths et al., 2006), than a commitment to IS.

One Australian student did ask the researcher why, if IS was such a great career for women, was there only one woman academic in the School of IS? This was a very pertinent question, and it is one that the researcher, the lone woman, has struggled with herself and echoes Trauth's call for more women IS academics (2002). Although the NZ University has two women out of nine lecturing staff, all four IS tutors are women. This gives the impression of a greater gender balance than actually exists as the tutors are responsible for practical labs and are not research active. Half of the students thought that a woman lecturer was employed to teach the first year course to make the subject "more accessible", implying that female academics are more suited to a nurturing role. This gender stereotyping was more evident on the part of the women than the men.

Failure to attract women into IT disciplines in academia must have a significant impact on the way the profession is viewed. The under-representation of women in IS schools does not go unnoticed by the students and may have a significant influence on the image of IT careers as a male dominated domain (Sumner \& Niederman, 2004; Trauth, 2002; von Hellens \& Nielsen, 2005).

\section{Gender Aptitude}

Anecdotal evidence or stereotyping suggests that males have great aptitude for the technical aspects of IS despite evidence to the contrary. A review of course results over the last three semesters at the Australian university highlights the fact that the High Distinctions in Introductory Information Systems are split fairly well into $75 \%$ for women and $25 \%$ for men, and the students who fail are split evenly between the two genders.

However, students seem to accept gender stereotyping and when asked which group would have greater aptitude for IS, 34 of the 36 students said that men would be better. When asked why, they thought that men had more logical minds, were better at computing because they played games all the time and experimented with software for their personal use, are able to use the technology more proactively, and enjoy technology more. When it was pointed out to the students that women tend to shine in IS, and that the top five students in the previous course were women, they all felt that this was a statistical aberration and that the women must have been "nerdy, mature age types". Two of the mature age women in the focus groups felt that they struggled with IS because they wanted to understand exactly how everything worked, although they did not feel like this about other 
technologies such as the telephone, television and motor car. Both students were in the top $10 \%$ of

the course. Comments from the women students suggested that they felt out of place in the classes: "minorities [women] feel they are in the wrong place. IS is a young male dominated, geeky, environment and we feel like interlopers." "Even though we have been told that girls do better than the boys, we feel that this has to be a generalisation. I know lots of girls who have failed, and I think I might fail. Even though it's not supposed to be technical, I struggle to understand some of the concepts... I mean, just how can this stuff work?"

These results were mirrored in the outcomes from NZ although the data were only available from one semester. Two of the three top students and nine out of the top twenty were women. Failure rates were relatively evenly split with slightly more males failing than women. Mature age women tended to succeed more than any other group and their experiences reflected those of the Australian students in that they felt they had to know and understand everything relating to IS technology.

\section{Further gender issues}

Further issues that turn women away from IS also reflect the literature on 'gendering' (Lee, 2005). The identification of IT as 'men's work' results from societal perception of gender roles. The male dominance in the IT workplace reinforces the identification of computing as something of little interest to women (Trauth, 2002).

Many of the women students said that they were not stimulated to learn about computers and IS, and saw technology either as a tool or as some science fiction fantasy with which they would probably never engage.

"I just can't get interested in it. The classes look at the future technologies and I can't get excited, even though I want to and I know that it will help me get a job."

It is tempting to assign essentialist theory and assert that these attitudes arise from inherent differences between the genders (Trauth, 2002). However, women students in NZ who were familiar with practical applications of technology in the workplace were more interested in computing and what could be done with it. Although their views supported the identification of technology as a tool, they did agree that social benefits of technologies such as the Internet and mobile phones were extensive and could be fun. Nevertheless, women saw themselves as users of the technology, rather than as drivers. They struggled to see themselves in a position where they would dictate IS policy within an organization, in spite of having studied numerous case studies that had women in roles of CIO.

Male participants could not think of many reasons why women would not want to study IS, particularly as there were so many men involved. This, of course, led two of the women to state that that would be exactly why they would not want to participate, again supporting the stereotyping of IT subjects as male dominated.

One NZ male student thought that IS would be a great job for women as they could work from home and "go part time if they had families". He also felt that women probably made better managers where men concentrated more on the 'computer stuff'. This is an illustrative example of a male student also having problems identifying IT careers without preconceptions and tending to adopt stereotyping as reality.

Another recurring theme was how 'boring' IS was at school and the women particularly, though not exclusively, had few good things to say about the subject as taught in schools.

"I did Systems at school, it was taught by a man, the class was full of boys who didn't wash, and who swore all the time, and the teacher never told them they were 
offensive. I was horrified when I found that I had to do an IS unit as part of my BBus - I tried to get an exemption". "I must say that I enjoyed the unit more than when I studied it at school. It was horrible there, smart arse boys who showed off”.

This echoes the findings of a government conference in NZ where the school IT curriculum was castigated by academics as failing to inspire pupils (Hendery, 2006). This is of concern for IS academics who must address students who have preconceptions of the subject as boring before they enter the lecture rooms. When initiatives such as WINIT (Griffiths \& Moore, 2006) and ITBeat (Lee, 2005) were discussed with students there was great enthusiasm for the idea that technology could be made relevant to women.

Although the focus groups and interviews were conducted in an attempt to understand the issues for women and IS, they did have the bonus benefit of helping to educate the students about the role of the IS professional.

"I must say that I have learned loads about IS through this process" "I have actually felt more part of the group during this session, than I do in the class - can we do more of these?"

In spite of extensive discussion of these issues in lectures, it was not until the students had to think about themselves that they could see that there were some possibilities. When asked if any of them had changed their minds about undertaking an IS major, three students said they would consider it when they received their exam results - unfortunately, none of the three were women.

"I'm beginning to understand what it's about, I've never really thought about it before. I still don't think it's the career for me - sorry."

\section{OUTCOMES FOR COURSE DEVELOPMENT}

Although women leaving the IS profession is a difficult issues for academics to address, the many women entering tertiary education that are exposed to Information Systems as part of their university course are our concern. These courses are an opportunity to highlight many of the positives of undertaking IS as a career. However, it is often at this point that we, the academics, fail to inspire women to continue with IS studies. We found from our data analysis that a key point raised by the female students was the need to make the course relevant to them. By this we are led to understand that female students fail to find the connection between the course content and their own understanding of the workplace. These students had difficulty relating to the course content in the abstract, but responded well to guest lecturers who presented real situations such as how information systems were implemented and where and why projects had failed. This was of particular importance where students had little personal contact with any IT professionals and industry speakers could be perceived as role models. These speakers also often emphasised the 'people' nature of IS as a career.

Women are often good at working in teams because of an inherent preference for connected knowing or learning, as opposed to separated learning (Morris, 2002). However, many find groupwork in university to be a frustrating experience particularly in large first-year groups where students, with diverse interests and skills, expend different degrees of effort. More use of online collaborative learning both peer to peer and student to lecturer is likely to encourage women who are more attuned to cooperative learning styles (Rajagopal \& Bojin, 2003). The use of chat-room discussions and promoting group-learning through discussions and emails appeals to women in a learning environment (Rajagopal \& Bojin, 2003). Greater application of such methods to IS courses would greatly benefit them and improve study methods. 
There is also a need to relate concepts to the personal experiences of students using an active handson approach. We have found that case studies to which the students can relate increases interest and promotes questioning. Case studies from the text books are not seen as 'real' and time taken to develop more 'live' material produces a better response. This is particularly true when case studies have a social element to which the students can directly relate (for example, health, non-profit and female-orientated cases).

One of the outcomes in the Australian University is a complete rewrite of the undergraduate degree. Part of the rewrite involves the introduction of four units based on integrated studies. These four units are taught outside of the normal school or department disciplines and involve staff from throughout the faculty teaching communications, numeracy, ethics, problem solving, negotiation, teamwork and information literacy through integrated activities. It is hoped that the women will enjoy learning about IS in the context of information literacy, and will utilise computers for a variety of purposes such as research, interpreting data, and writing and presenting reports. The students will create e-portfolios and gain career advice as part of one unit, and there will be a strong push to expose them equally to all the disciplines offered by the faculty. The new subset of units will also involve industry and employers, and there will be a series of lectures and networking opportunities for the students. Several women CIOs have been identified as being important for this part of the program, and it is hoped that they will be able to inspire more female students to join the profession. This is in line with the proposed action in the Business/Higher Education Round Table report (BHERT, 2005).

In the NZ University, the approach to date has been more low-key. IS sits in the Science Faculty, which raises barriers in the minds of our business students despite the introduction of a joint business/IS major. The discipline has developed along more technical lines over the years than many other IS departments due to its co-location with other IT related disciplines. To counteract this we have recently identified and promoted a business pathway through the degree programme to enable students to choose the emphasis of their IS degree. The first year course has two academics appointed to reform the content over a period of three years to make it more accessible and relevant to the students from IS and other disciplines. Interactive, visual teaching aids are being developed to present technical concepts to the students and plans are underway to encourage third year and postgraduate projects to develop multimedia learning programmes for first year students. Guest speakers, although difficult to find, have been used to great effect and other lecturers from within the discipline group have also contributed talks on their research areas. This approach has been very well received by students who have been able to relate IS to the 'real world'.

\section{RECOMMENDATIONS FOR MARKETING IS COURSES}

Marketing of courses is not traditionally a responsibility of academics. However, in the current climate of tertiary education there needs to be recognition of the economic realities and the need to attract students to our own courses.

Marketing is of paramount importance in attracting women into IS courses. The influence of parents should not be overlooked (Morris, 2002) and therefore there is a need to target parents at open days and encourage families to IS display. The Australian university is creating a set of materials that will provide prospective students with better publicity about IS and more enjoyable experiences through interactive displays. One female graduate from the School is now a high ranking IS professional within a large organisation, and another is a Chief Information Officer. They have been interviewed on video and the recording is now used as promotional material for the school. It is too 
early to determine whether this approach will make a difference, but it is proposed to use the video as part of a focus group research item to see whether the students feel that it makes a difference.

The NZ university has revised its promotion of IS courses to emphasise the 'business pathway' through the courses offered. It has also taken more control of planning for open days (previously left to the university administrators) and gained a role in both the Science and Business Faculties parents' evenings. Marketing events now emphasise the 'people, technology, information' definition of IS. It is intended that such initiatives should overcome the 'geek' image problem expressed by the students in the study, and have a more positive influence on prospective students before they enrol.

Further marketing initiatives need to be encouraged at school level. The Women in ICT Task Force Report (BHERT, 2005) argues that in order to attract women into computer-related professions, 'educators need to broaden the meaning and improve the values associated with the computer per se as a tool for productive and creative technological work across the life-career stages' (p.26). This report also identified the lack of women role models in the media; for example, there are no female IT professionals in sitcoms. In order to attract younger women into IT courses, career development officers and teachers in schools should be targeted, as there is no doubt that these people do make a difference to subject selection and impressions about academic disciplines.

Finally, on a more general note, we have found that university marketing personnel often have little idea of what any IT related courses entail and therefore do not highlight them to schools. More interaction with university marketing departments by IT academics is a necessary step to improving enrolments of either gender.

\section{REFLECTIONS AND CONCLUSIONS}

We reached some conclusions from this study on action that we could take to improve the interest levels of these introductory IS courses for female students as discussed in the outcomes and marketing sections above. However, our collaboration also led us to reflect on other influences that affect the way such courses are presented and which are, to a great extent, beyond the control of individual lecturers.

From a university perspective the low numbers of women in IT is reflected in both the student and academic bodies. Both universities in this study suffer from an imbalance between male and female IS academics. The whole discipline of Information Systems needs to encourage the appointment of more female role models. The need for more women academics is impacted by a shortage of women graduates and this "catch 22" situation needs to be addressed urgently if we are to encourage more women into IS degrees.

From a strategic perspective a reworking of the curriculum at both secondary and tertiary levels would be of benefit to improve the content of such courses and make them more personally relevant to both men and women. From an academic perspective, course content and delivery must be improved and more closely related to the key elements of technology, business and social issues and the effect of IT on people and their lives. This, we believe, is a difficult task when the contribution of information systems as a discipline does not retain a high regard within the current university climate, following the downturn in student numbers in recent years.

There is a division between IS academics as to whether IS should be regarded as a technical or a business orientated discipline. The two universities in this study approach delivery of courses from 
different perspectives with one course being delivered from a business faculty and one from a science faculty. Recent changes in both universities reflect our perception of the downgrading of the value of information systems. The School of Information Systems in Australia has lost its identity by being subsumed into the School of Management with further restructuring of the course to 'make it appeal to employers'. There is little apparent cognisance of the need to attract more women (and men) into IS degrees in these changes. In the NZ university an artificial 'division of the body of knowledge' has resulted in any business-related content being moved to the business faculty while the existing discipline group retains responsibility for delivery of the technical content. This move could be seen to mirror the divisions in the workplace which IS textbooks highlight as a significant cause of systems inefficiencies.

Generating a gender balance by making first year IS courses more interesting for women is a necessary step towards improving their representation in IT-related careers in the workplace. This requires constant reflection on the nature and content of these courses, but also requires that the discipline achieves greater recognition both within universities and in industry. Academics must play a part in this and step outside their teaching role to take a hands-on approach to addressing the drab image of the IT professions. They need to work towards greater appreciation of the value of the IS discipline and towards ensuring that marketing of their courses informs industry, prospective students, their parents and careers advisors of the true nature, content and value of information technology degrees.

\section{LIMITATIONS AND FURTHER RESEARCH}

This research addresses the presentation and content of introductory IS courses. It is also written from the perspective of two women academics and does not address the views of male colleagues.

More research into the progress of students through second and third year IS courses would contribute to a clearer picture of how not only to encourage but also retain students. Such research should also address the questions raised from both male and female perspectives to ensure that a more holistic view is given.

At the university level we believe that any dominance of male characteristics in system design, human/computer interaction and programming needs to be more clearly addressed, together with developing an emphasis on usability that is more appealing to women.

Specific research on how to teach women so that the discipline appeals to them should continue to be conducted. There is a scarcity of literature, although there are now several academics actively conducting research in this area. A review of a similar problem within the sciences highlights the fact that such research has been happening in the pure sciences for a long time and has salient lessons for the information systems discipline.

\section{REFERENCES}

Armstrong, D., Riemenschneider, C., K, Reid, M., \& Allen, M. (2004) "Voluntary turnover and women in IT: A cognitive study of work-family balance”. Proceedings of the Fourth Annual SIG IS Cognitive Research Workshop, Washington, DC. 
Baroudi, J., \& Igbaria, M. (1995). “An examination of gender effects on career effects of information systems employees”. Journal of Management Information Systems, Vol 11 No 3, pp 181-201.

BHERT. (2005). "The gender gap in the ICT industries: Failing to fully utilise a national resource” Joondalup, WA: Business/Higher Education Round Table. Edith Cowan University, Report 106.

Christensen, R., Knezek, G., \& Overall, T. (2005). “Transition points for the gender gap in computer enjoyment” Journal of Research on Technology in Education, Vol 38 No 1, pp 2337.

Denning, P., J, \& McGettrick, A. (2005). "Recentering computer science”. Communications of the ACM, Vol 48 No 11, pp 15-19.

Department for Women. (2002). “Information technology framework. Government of NSW. Available online at: http://www.women.nsw.gov.au/PDF/Archived/ 2002\%20Information\%20Technology\% (accessed 6 June 2006).

Department of Labour. (2005). "Information technology professional: Occupational skill shortage assessment”. Wellington. http://www.dol.govt.nz accessed 10 July 2006.

Goodwin, B. (2006). “Better networking keeps men in top IT jobs, research suggests”. Computer Weekly, p 42.

Griffiths, M., Keogh, C., Moore, K., Tattersall, A., \& Richardson, H. (2006). "Managing diversity or valuing diversity? Gender and the IT labour market”. Working paper, Information Systems Institute, University of Salford, Manchester.

Griffiths, M., \& Moore, K. (2006). “Issues raised by women in IT (WINIT) Project in England”. In E. Trauth (Ed.), Encyclopaedia of Gender and Information Technology. Ideas Group, Hershey, PA.

Hargittai, E., \& Shafer, S. (2006). "Differences in actual and perceived online skills: The role of gender”. Social Science Quarterly, Vol 87 No 2, pp 432-448.

Hendery, S. (2006). “IT grappling with image problem”. NZ Herald. http://www.nzherald.co.nz accessed 11 July 2006.

Jewell, H., \& Maltby, J. (2002). "Female involvement in information technology degrees: Perception, expectation and enrolment”. Proceedings of the 12th Australasian Conference on Information Systems, Coffs Harbour, NSW.

Lang, C. (2003). "How girls make decisions about education and careers in information technology”. University of Melbourne, PhD Confirmation Document. http://www.ict.swin.edu.au/personal/clang/ accessed 4 July 2006.

Lee, L. (2005). “Tackling technology's image problem among young girls”. The International Journal of Sociology and Social Policy, Vol 10/11, pp 119-130.

Moore, K., Griffiths, M., \& Richardson, H. (2005). “Moving In, Moving Up, Moving Out? A Survey of Women in ICT”. Symposium on Gender and ICT; Working for Change. Manchester.

Morris, L. D. (2002). “Women in information technology literature review: Recruitment, retention and persistence factors”. In A. M. o. t. M.-s. E. R. Association (Ed.). Chattanooga: Educational Resources Information Center, US Dept. of Education. 
Pinkard, N. (2005). "How the perceived masculinity and/or femininity of software applications influences students' software preferences”. Journal of Educational Computing Research, Vol 32 No 1, pp 57-78.

Rajagopal, I., \& Bojin, N. (2003). “A gendered world: Students and instructional technologies”. First Monday, Vol 8 No 1. http://www.firstmonday.org accessed 18 June 2006.

Rossi, S. (2006). “Aussies seek local recruits, but women still spurn IT”. Computerworld New Zealand. http://www.computerworld.co.nz accessed 3 July 2006.

Stone, P. (2007). “Opting out? Why women really quit careers and head home”. University of California Press, Berkeley, CA.

Sujdak, E. J. (2002). "Impact of the shortage of IT professionals on logistics and supply chain management”. Logistics Spectrum Apr-June.

Sumner, M., \& Niederman, F. (2004). “The impact of gender differences on job satisfaction, job turnover, and career experiences of information systems professionals”. Journal of Computer Information Systems, Winter, pp 29-39.

Trauth, E. (2002). "Odd girl out: an individual differences perspective on women in the IT profession”. Information Technology and People, Vol 15 No 2, pp 98-118.

von Hellens, L., \& Nielsen, S. (2005). “Australian women in IT”. Communications of the ACM, Vol 44 No 7, pp 46-52. 
